\title{
Factors influencing the bronchodilator effect of a deep inspiration in asthmatic patients with provoked bronchoconstriction
}

\author{
A BEAUPRÉ, J OREHEK \\ From the Laboratoire d'Explorations Fonctionnelles Respiratoires, Hôpital Salvator, and INSERM U-174, \\ Marseille, France
}

ABSTRACT We have studied 26 asthmatic patients in whom a deep inspiration induced a transient but marked bronchodilatation when carbachol-induced bronchoconstriction was present. Changes in bronchial tone were assessed by specific airway resistance measurements. Bronchodilatation after a slow inspiration (eight subjects) or a 10 -second breath-hold at total lung capacity (13 subjects) was significantly less than that observed after either a fast inspiration or no breath-holding period. The magnitude of the bronchodilatation induced by a fast inspiration without breath-holding was directly and significantly related to the magnitude of the carbachol-induced bronchoconstriction in five subjects.

When bronchoconstriction is induced with pharmacological agents in asthmatic patients, a deep inspiration has little bronchomotor effect in some whereas in others it causes a transient but large bronchodilatation. ${ }^{12}$ In the latter, the forced expiratory volume in one second $\left(\mathrm{FEV}_{1}\right)$ can be unsuitable to assess increased bronchial tone, because the deep inspiration preceding the forced expiratory manoeuvre abolishes the induced bronchoconstriction. ${ }^{3}$ Usually, neither the flow rate of the deep inspiration preceding the forced expiration, nor the duration of the breath-holding period before expiration, are controlled. This study was undertaken to determine the possible influence of these two variables on the bronchodilator effect of a deep inspiration.

We also investigated whether the bronchodilator effect of a deep inspiration was related to the magnitude of the provoked bronchoconstriction.

\section{Methods}

Twenty-six patients (mean age \pm SE $36 \mathrm{yr} \pm 3 \cdot 1$; 13 females), referred to our laboratory for routine bronchial provocation tests, were studied. All suffered from bronchial asthma as defined by the American Thoracic Society 4 and in all a deep inspiration resulted in bronchodilatation after

Address for reprint requests: Dr J Orehek, Hôpital Salvator, 249 chemin de Ste-Marguerite, 13009 Marseille, France. carbachol-induced bronchoconstriction. Their clinical state was stable and they denied any airway infection in the preceding six weeks. All medications were withheld from at least 12 hours before the tests.

Functional residual capacity (FRC) and specific airway resistance (sRaw), determined at lung volume close to FRC, were measured with a constant volume body plethysmograph (DR 8 Amplifier, Electronics for Medicine, White Plains, NY) using the panting technique. ${ }^{56}$ The flow signal at the mouth, from a Fleisch no 2 pneumotachograph, was integrated to obtain the inspiratory volume and both signals were continuously recorded (Mingograph 800, Elema-Schönander, Stockholm). From the volume recording we calculated the mean inspiratory flow rate (ratio of inspired volume to 윽 inspiratory time) and the sRaw measurement time, $\rightarrow$ representing the time elapsed from the beginning of the expiration after the deep inspiration, to the N closure of the mouth shutter for sRaw measurements.

The patients were divided into three groups. In $\tilde{O}$ the first group composed of eight subjects (group A), $\underset{\omega}{ }$ we induced bronchoconstriction with aerosolised $\sigma$ carbachol according to the technique previously described. ${ }^{7}$ Specific airway resistance $\left(\mathrm{cm}^{\mathrm{H}} \mathrm{H}_{2} \mathrm{O}\right.$. s) increased from $8.78 \pm 0.80$ to $25.7 \pm 1.32$, and $\stackrel{\odot}{+}$ FRC (1) from $2.93 \pm 0.19$ to $3.70 \pm 0.24$ (mean 0 \pm SE). The subjects then performed two deep and $\bar{D}$ very fast inspirations and two deep and very slow $\stackrel{\mathbb{D}}{\Omega}$ inspirations, in a random order.

In the second group composed of 13 subjects 
Table Mean values $( \pm S E)$ of the measured variables in groups $A$ and $B$. The variables involved in the matched observations did not differ significantly, except in patients of group $A$ where $\dot{V} i$ was significantly different by experimental design. In patients of group $B$ the only difference was the presence or absence of a 10-second breath-hold at total lung capacity

\begin{tabular}{|c|c|c|c|c|c|}
\hline $\begin{array}{l}\text { Groups } \\
(n)\end{array}$ & Experimental protocol & $\begin{array}{l}\text { sRaw before } \mathrm{DI} \\
\left(\mathrm{cm} \mathrm{H}_{2} \mathrm{O} . \mathrm{s}\right) \ddagger\end{array}$ & $\begin{array}{l}\overline{\dot{V}} i \\
(l / s)\end{array}$ & $\begin{array}{l}V i \\
(I)\end{array}$ & $\begin{array}{l}\text { sRaw measurement } \\
\text { time after DI } \\
(s)\end{array}$ \\
\hline \multirow{2}{*}{ Group A (8) } & High $\overline{\mathrm{V}} \mathrm{i}$ & $\begin{array}{l}25.40 \\
\pm 1.77\end{array}$ & $\begin{array}{r}1.54^{\circ} \\
\pm 0.18\end{array}$ & $\begin{array}{r}2.29 \\
\pm 0.24\end{array}$ & $\begin{array}{r}7.41 \\
\pm 0.52\end{array}$ \\
\hline & Low $\overline{\mathbf{V}}_{\mathbf{i}}$ & $\begin{array}{l}26 \cdot 20 \\
\pm 1 \cdot 46\end{array}$ & $\begin{array}{c}0.54^{*} \\
\pm 0.04\end{array}$ & $\begin{array}{r}2.23 \\
\pm 0.24\end{array}$ & $\begin{array}{r}8.03 \\
\pm 0.75\end{array}$ \\
\hline \multirow{2}{*}{ Group B (13) } & Without breath-holding & $\begin{array}{r}20 \cdot 30 \\
\pm 1 \cdot 54\end{array}$ & $\begin{array}{r}1 \cdot 36 \\
\pm 0 \cdot 13\end{array}$ & $\begin{array}{r}2 \cdot 10 \\
\pm 0 \cdot 17\end{array}$ & $\begin{array}{r}7 \cdot 70 \\
\pm 0.63\end{array}$ \\
\hline & With breath-holding & $\begin{array}{r}19.70 \\
\pm 1.51\end{array}$ & $\begin{array}{r}1.31 \\
\pm 0.13\end{array}$ & $\begin{array}{r}2.17 \\
\pm 0.14\end{array}$ & $\begin{array}{r}6.90 \\
\pm 0.36\end{array}$ \\
\hline
\end{tabular}

sRaw: specific airway resistance; Dl: deep inspiration; $\overline{\mathrm{V}} \mathrm{i}$ : mean inspiratory flow rate of deep inspiration; Vi: inspiratory volume of deep inspiration; *difference significant with paired $t$ test $(p<0.001)$; time elapsed from the beginning of the expiration, after the deep inspiration, to the closure of the mouth shutter for sRaw measurement; $\$ 1 \mathrm{~cm} \mathrm{H}_{2} \mathrm{O} . \mathrm{s}=0.1 \mathrm{kPa}$. s.

(group B), bronchoconstriction was similarly induced. Specific airway resistance $\left(\mathrm{cm} \mathrm{H}_{2} \mathrm{O} . \mathrm{s}\right)$ increased from $6.64 \pm 0.47$ to $21.3 \pm 1.5$ and FRC (l) from $2.59 \pm 0.14$ to $3.43 \pm 0 \cdot 15$. The subjects were then instructed to perform, in random order, two deep inspirations, each followed by a 10-second breath-holding period at TLC, and two deep inspirations without any breath-holding. For these deep inspirations, the subjects inspired as fast as possible. In both groups A and B, sRaw was measured immediately and at 15-second intervals after every deep inspiration. The following deep

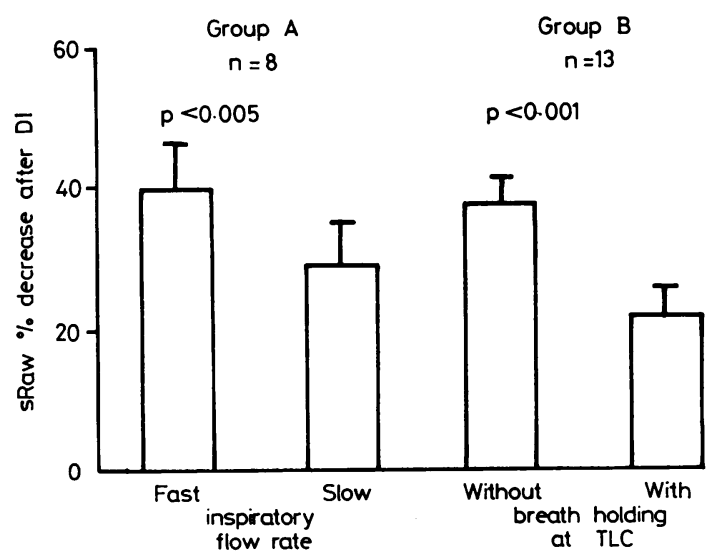

Fig 1 Influence of varying the inspiratory flow rate (group $A$ ) and of maintaining a 10-second breath-hold at total lung capacity (group $B$ ), on the decrease in specific airway resistance ( $s$ Raw) induced by a deep inspiration (DI) in asthmatic patients with carbacholinduced bronchoconstriction. inspiration was performed only when sRaw had returned to its pre-deep inspiration value. The inspiratory volume and the time of sRaw measurement after the deep inspiration, both factors known to affect the deep inspiration-induced bronchodilatation, ${ }^{2}$ did not differ significantly in either group for the matched observations (table).

In a third group of five patients (group C), sRaw was gradually increased by administering repeated doses of aerosolised carbachol, and we measured the effect of one deep inspiration (fast inspiratory flow rate and no breath-hold) on sRaw after each carbachol dose. Specific airway resistance measurements were done immediately and at 15 -second intervals after every deep inspiration until sRaw had returned to its pre-deep inspiration value. Only then was a subsequent dose of carbachol administered.

For all three experimental protocols, only the first sRaw measurement after each deep inspiration was used for calculations, and in both groups $A$ and $B$ we analysed the mean sRaw modification induced by two identical inspiratory manoeuvres. The least square method and Student's paired $t$ test were used for statistical calculations $;^{8} p$ values less than 0.05 were considered as significant.

\section{Results}

The bronchodilator effect of a deep inspiration was significantly decreased when the inspiratory manoeuvre was performed slowly, and when the deep inspiration was followed by a 10-second breathholding period at TLC (fig 1).

In protocol $\mathrm{C}$, before carbachol, a deep inspiration had little bronchomotor effect in two patients whereas it caused an sRaw increase in three others (fig 2). 

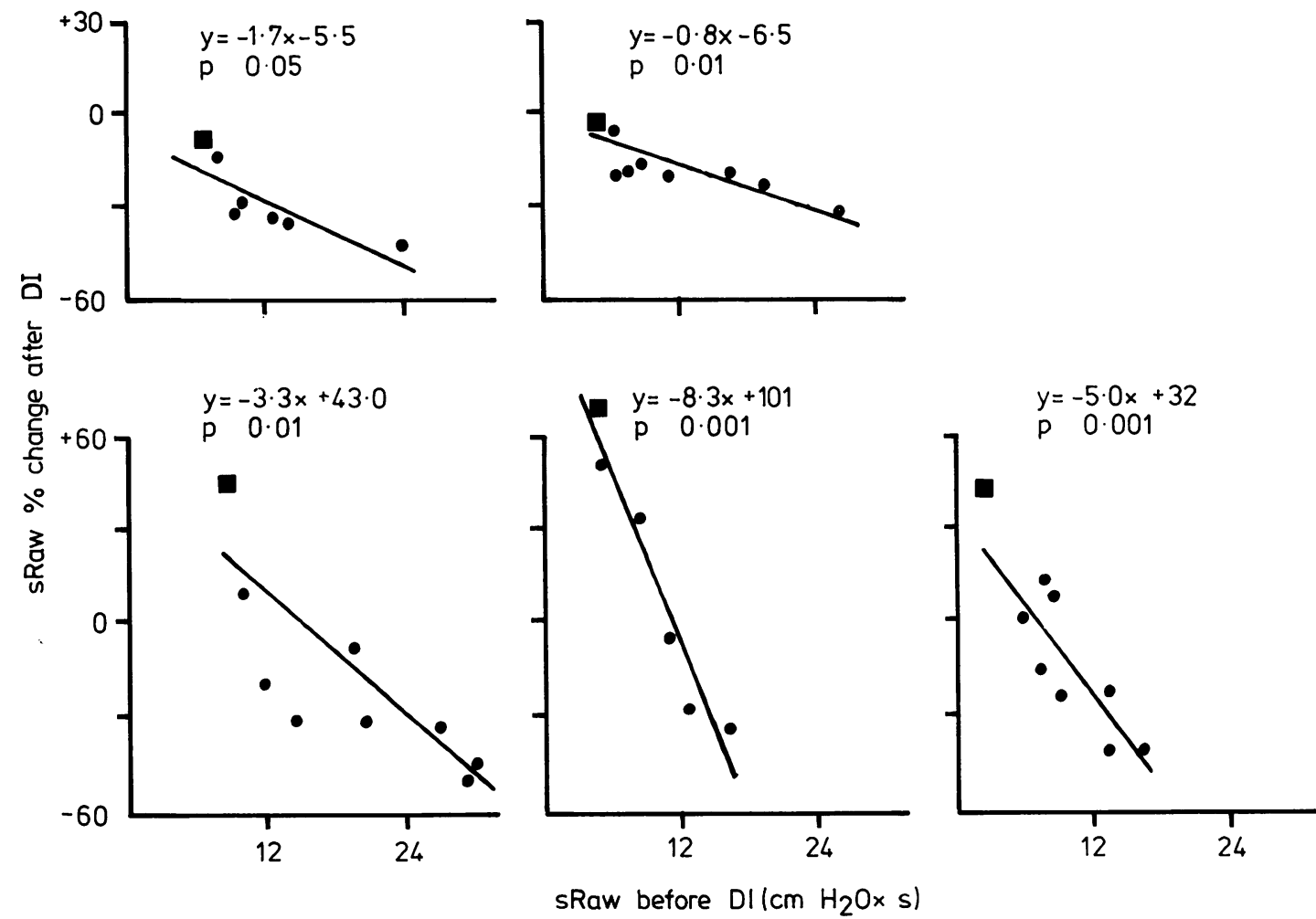

Fig 2 Relationship between the percentage change in specific airway resistance (sRaw, ordinate) induced by a deep inspiration (DI), and the pre-deep inspiration value of sRaw (abscissa) in the five asthmatic patients of group C.

The values of sRaw were gradually increased from the baseline conditions ( $)$ by administering cumulative doses of aerosolised carbachol. Each panel represents the results for one individual. The regression lines were calculated by the method of least squares.

When carbachol-induced bronchoconstriction was present, a decrease in sRaw was observed in all five patients after a deep inspiration, the magnitude of which was positively correlated with the magnitude of the pre-deep inspiration bronchoconstriction (fig 2). Statistically significant correlations were also observed when the changes in sRaw after deep inspiration were expressed as absolute values instead of percentages.

\section{Discussion}

When pharmacologically-induced bronchoconstriction is present, a deep inspiration has a marked bronchodilator effect in normal subjects, ${ }^{9}$ in patients with hay fever, ${ }^{1}$ and in a few asthmatics. ${ }^{12}$ This effect is of short duration ${ }^{1.29}$ and in this study we observed that it was less pronounced after a 10second breath-holding period at TLC. This suggests that the bronchodilatation started to disappear as soon as the subjects reached TLC. Such a restoration of bronchial tone after a brief period of apnoea at submaximal inspiratory volume has been observed in normal man with unstimulated airways. ${ }^{10}$

The magnitude of the deep inspiration-induced $\bigcirc$ bronchodilatation is related to the inspiratory volume. $^{2}$ This study shows that it is also related to the inspiratory flow rate and to the degree of $N$ pharmacologically-induced bronchoconstriction. The latter finding contrasts with a previous study in $N$ which we observed that a deep inspiration had a $\underset{\omega}{N}$ more pronounced bronchoconstrictor effect in asthmatic patients with marked spontaneous air- $c$ way obstruction. ${ }^{11}$ This suggests that the pharma- $\frac{\mathscr{D}}{\mathscr{N}}$ cologically-induced airway obstruction differs from $\stackrel{\oplus}{+}$ the spontaneous airway obstruction observed in 0 asthmatic patients.

The exact mechanism underlying the bronchodilatation induced by a deep inspiration is still unclear. The airways are imbedded and tethered in 
the lungs and participate in their volume changes, increasing in calibre during inspiration and decreasing during expiration. In addition these two structures present hysteresis which has opposing effects upon airway calibre. After a lung inflation, lung tissue hysteresis results in a transient decrease in transpulmonary pressure measured at FRC 12 which could result in decreased airway calibre and increased resistance. In contrast, airway hysteresis after a lung inflation results in increased airway calibre and decreased resistance for the same transpulmonary pressure. ${ }^{13}$ Since sRaw decreased after a lung inflation in our patients, it follows that airway hysteresis must have dominated lung tissue hysteresis. 1314

In isolated airways the importance of hysteresis has been related to the degree of airway constriction. ${ }^{15}$ The relationship we observed between the bronchodilator effect of a deep inspiration and the level of induced bronchoconstriction is consistent with this study. This association was also probably enhanced by the hyperbolic relationship between airway resistance and airway diameter: the same change in airway diameter after a lung inflation would induce a larger change in airway resistance if resistance was large before inspiration than if it was small.

The flow-related differences we observed could also be explained by airway hysteresis if they were more related to the peak flow generated rather than to the average inspiratory flow. If this were the case, one could explain the results on the basis of a difference in the pressure drop across the airways; hence, at higher peak inspiratory flow rates, there would be a greater transmural airway distending pressure during the dynamic inspiratory manoeuvre and airways would be more vigorously stretched, increasing airway hysteresis. With respect to the effects of breath-holding time at TLC, our results are consistent with previous reports of time dependence of airway hysteresis in excised dog lungs. ${ }^{15} 16$

In vivo, other mechanisms may also have come into play to modify airway hysteresis. Stretch receptor mediated bronchodilatation could explain why the magnitude of the deep inspiration-induced bronchodilatation was positively correlated with the magnitude of airway constriction, since stretch receptor activation is faciliated by increased bronchial tone. ${ }^{17}$ Indeed, increase in bronchial tone favours the bronchodilator response to lung inflation in dogs. ${ }^{18}$ Stretch receptor activation has been shown to be positively correlated with the inspiratory flow rate, ${ }^{19}$ and a reflex mediated by these receptors could thus explain why the bronchodilator effect of a deep inspiration was accentuated by a fast inspiratory flow rate. On the other hand, stretch receptor adaptation to continuous stimulation is slow $^{20}$ and cannot explain why the deep inspirationinduced bronchodilatation diminished after a 10second breath-holding period at TLC.

Lung inflation releases prostaglandins of the $\mathrm{E}$ and $F$ series. ${ }^{2122}$ The action of prostaglandin $E$ on isolated guinea-pig trachea is related to smooth muscle tone: it contracts the relaxed preparations and relaxes the contracted ones. Such a release could thus explain why the bronchodilator effect of a deep inspiration was related to the degree of bronchoconstriction in our study. The amount of protaglandins released with lung inflation is related to tidal volume. ${ }^{2122}$ It is apparently not known if prostaglandin release is influenced by changing the inspiratory flow rate. If the bronchodilator effect of a deep inspiration is mediated by a humoral mechanism, the diminution of this effect with a 10 -second breath-holding period could be explained by assuming that the humoral agent released was shortlived.

Whatever the exact mechanism underlying the bronchodilator effect of a deep inspiration in our patients, the present observations may have practical implications. We have previously observed that the bronchomotor effect of the preceding deep inspiration influences the subsequent change in $\mathrm{FEV}_{1}$ in asthmatic patients undergoing bronchial provocation tests: ${ }^{3}$ it can produce false negative tests in patients having a large inspiratory bronchodilator effect. The present study suggests that the influence of deep inspiration on $\mathrm{FEV}_{1}$ measurements could be minimised in such patients if the forced expiration was preceded by a slow inspiration and a prolonged breath-holding period at TLC.

We would like to thank Ms C Augusto for technical assistance, to Mrs C Giuntini for typing the manuscript, and Dr DG Massey for revising the language of the text. A Beaupré is the recipient of a grant from the Conseil de la Recherche en Santé du Québec.

\section{References}

${ }^{1}$ Fish JE, Peterman VI, Cugell DW. Effect of a deep inspiration on airway conductance in subjects with allergic rhinitis and allergic asthma. J Allergy Clin Immunol 1977;60:41-6.

${ }^{2}$ Orehek J, Charpin D, Velardocchio JM, Grimaud C. Bronchomotor effect of bronchoconstriction-induced deep inspirations in asthmatics. Am Rev Respir Dis $1980 ; 121: 297-305$.

${ }^{3}$ Orehek J, Nicoli M, Delpierre S, Beaupré A. Influence of the previous deep inspiration on the spirometric measurement of provoked bronchoconstriction in asthma. $\mathrm{Am}$ Rev Respir Dis $1981 ; 123: 269-72$.

${ }^{4}$ American Thoracic Society. Chronic bronchitis, asthma 
and pulmonary emphysema. A statement by the Committee on Diagnostic Standards in non tuberculous respiratory disease. Am Rev Respir Dis 1962;85:762-9.

${ }^{5}$ Dubois AB, Botelho SU, Bedell GN, Marshall R, Comroe JH Jr. A rapid plethysmographic method for measuring thoracic gas volume: a comparison with a nitrogen washout method for measuring functional residual capacity in normal subjects. J Clin Invest 1956;35:322-6.

${ }^{6}$ Dubois AB, Botelho SU, Comroe JH Jr. A new method for measuring airway resistance in man using a body plethysmograph: values in normal subjects and in patients with respiratory diseases. $J$ Clin Invest 1956; 35:327-35.

7 Orehek J, Massari JP, Gayrard P, Grimaud C, Charpin J. Effect of short-term, low-level nitrogen dioxide exposure on bronchial sensitivity of asthmatic patients. J Clin Invest 1976;57:301-7.

${ }^{8}$ Diem K. Tables scientifiques. Basle: Geigy SA, 1969.

${ }^{9}$ Nadel JA, Tierney DF. Effect of a previous deep inspiration on airway resistance in man. $J$ Appl Physiol 1961;16:717-9.

10 Green M, Mead J. Time dependence of flow-volume curves. J Appl Physiol 1974;37:793-7.

11 Gayrard P, Orehek J, Grimaud C, Charpin J. Bronchoconstrictor effects of a deep inspiration in patients with asthma. Am Rev Respir Dis 1975;111:433-9.

${ }^{12}$ Sharp JT, Johnson FN, Goldberg NB, Van Lith P. Hysteresis and stress adaptation in the human respiratory system. J Appl Physiol 1967;23:487-97.

${ }^{13}$ Froeb HF, Mead J. Relative hysteresis of the dead space and lung in vivo. $J$ Appl Physiol 1968;25:244-8.

14 McFadden ER, Ingram RH. Clinical application and interpretation of airway physiology. In: Lenfant C, Nadel JA, eds. Physiology and pharmacology of the airways. New York: Marcel Dekker, 1980:297-324.

${ }^{15}$ Sasaki H, Hoppin GH. Hysteresis of contracted airway smooth muscle. J Appl Physiol 1979;47:1251-62.

${ }^{16} \mathrm{Hahn} \mathrm{HL}$, Watson A, Wilson AG, Pride NB. Influence of bronchomotor tone on airway dimensions and resistance in excised dog lungs. J Appl Physiol 1980;49:270-8.

17 Widdicombe JG. The activity of pulmonary stretch receptors during bronchoconstriction, pulmonary oedema, atelectasis and breathing against a resistance. $J$ Physiol (Lond) 1961 ;159:436-50.

${ }^{18}$ Stein JF, Widdicombe JG. The interaction of chemo and mechano-receptor signals in the control of airway caliber. Respir Physiol 1975;25:363-76.

19 Davis HL, Fowler WS, Lambert EH. Effect of volume and rate of inflation and deflation on transpulmonary pressure and response of pulmonary stretch receptors. Am J Physiol 1956;187:558-66.

20 Paintal AS. Vagal sensory receptors and their reflex effects. Physiol Rev 1973;53:159-237.

${ }^{21}$ Berry EM, Edmonds JF, Wyllie JH. Release of prostaglandins $E_{2}$ and unidentified factors from ventilated lungs. Br J Surg 1971;58:189-92.

${ }^{22}$ Said SI, Kitamura S, Yoshida T, Preskitt J, Holden LD. Humoral control of airways. Ann NY Acad Sci 1974; 221:103-14. 